\title{
Optic Disc Detection in Fundus Eye Images - A Detailed Survey
}

\author{
Prakash. $\mathrm{J}^{1}$, Vinoth Kumar. $\mathrm{B}^{2}$ \\ \{1jpk.cse@psgtech.ac.in, ${ }^{2}$ bvk.it@psgtech.ac.in\} \\ ${ }^{1}$ Department of Computer Science \& Engineering, PSG College of Technology, ${ }^{2}$ Department of \\ Information Technology, PSG College of Technology, india.
}

\begin{abstract}
Detection of Optic Disc is an important task in the automatic retinal disease screening system. From the literature, it is identified that diabetic retinopathy is the main reason for blindness among working people especially aged people. Identifying and curing diabetic retinopathy at the earlier stages may prevent the cause of blindness among people. In this paper, a detailed survey involving the various techniques in optic disc detection like Morphological Operation Technique, Hough transform Technique, Evolutionary computing technique, and Machine learning technique are made from various literature works. This paper also discusses the various publicly available dataset that could be useful in assessing the performance of the various techniques. It also discusses the result obtained from the various methods proposed by different scholars in this domain and emphasize the enhancement obtained by them.
\end{abstract}

Keywords: Optic disc, Morphological operation, Hough transform, Evolutionary computing technique, Machine learning, soft exudates, hard exudates.

\section{Introduction}

The international diabetic federation shows that with around 422 million population (World Health Organization Global Report on Diabetic, 2016), where One out of Eleven has diabetic retinopathy. People who have diabetes will have diabetic retinopathy. The southern part of India has around $12.2 \%$ to $18.03 \%$ of the population already has diabetes. It's estimated that in Chennai $28.2 \%$ of the people have diabetes. Diabetes mellitus is a term used by doctors to describe a set of metabolic disorders in which a person has excessive blood sugar levels due to insufficient insulin production or a failure of the body's cells in responding effectively to insulin. The rates of diabetes mellitus were found to be higher in males (53.4\%) than females (46.6\%) in the Coimbatore zone, according to the research (Scholars Research Library).

Diabetes retinopathy is because of the side-effect of prolonging diabetes, which is related to the human eye. The launch point for ganglion cell axons leaving the eye is called the optic nerve head or optic disc as shown in figure 1.1. The dampening of blood vessels is because of an increase in sugar level which results in blood leakage or fluid substance deposited under macular edema termed as exudates. Exudates are divided into two major types: Soft exudates and Hard exudates as shown in figures 1.2 and 1.3 respectively.

Diabetic retinopathy is due to the formation of exudates. Diabetic retinopathy is classified into two types as Proliferative Diabetic retinopathy and non-Proliferative diabetic retinopathy, 
where the Non-Proliferative diabetic retinopathy is known as the phase without any abnormal vessel growth which directs to the blood vessel swelling termed as a microaneurysm. Therefore, the blood vessels give away the fluids which will deposit under the macular edema to form hard exudates.

Based on the retina findings, the retina is classified as early stage (which has only one or two microaneurysms), moderate stage (multiple microaneurysms and venous bleeding), and severe stage (venous bleeding and intra-retinal microvascular abnormalities). Around $75 \%$ of people are affected by Proliferative Diabetic Retinopathy.

Hard exudates are appearing similar to optic disc which looks in bright yellowish color. In order to detect hard exudates, the optic disc must be removed from the retinal image. As a result, one of the most essential procedures in the identification of exudates is the removal of the optic disc [1][5][6]. The major stages in the automatic detection method of optic disc [21] are pre-processing, feature extraction, segmentation of optic disc, and elimination of optic disc. The main goal of the paper is to review popularly used algorithm for detecting optic disc in an eye fundus image. Literature discloses that the various soft computing methods are applied in many scenarios as image processing application and prediction [24-27].

The remainder of this work is arranged as follows: the following section discusses retinal image processing for optic disc removal. Various dataset available in literature in Section 3, A survey on Optic disc Detection on Morphological operation, Hough Transform, Machine Learning, Evolutionary computing technique and classification are given in section 4 . followed by the section 5 on performance analysis and the final thought and future works is summarized at Conclusion part 6.

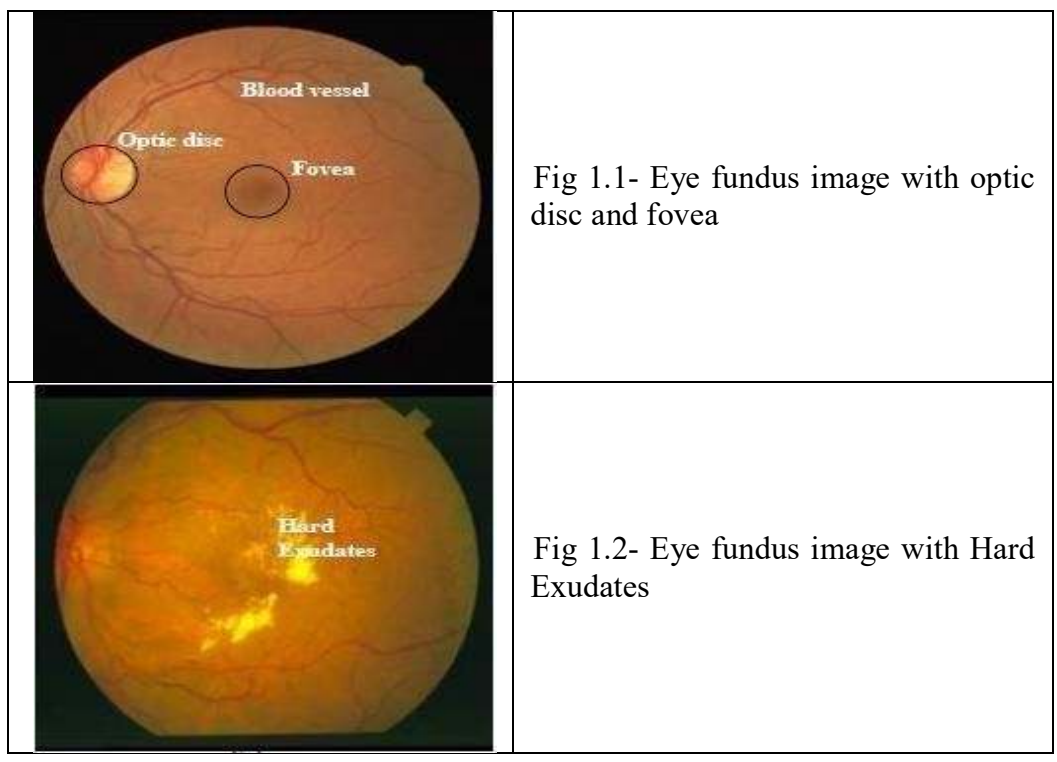




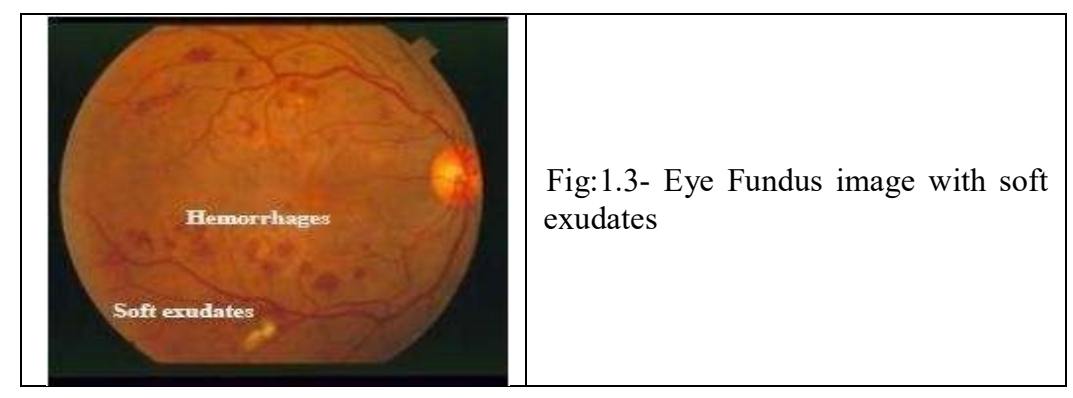

Retinal Image Processing For Optic Disc Elimination

Retinal image processing is done to spot the eye fundus images optic disc, as shown in figure 2.1. At first input image is taken from retinal datasets. Here different datasets such as Stare dataset, Drive dataset, Roc dataset, ImageRet Dataset, Messidor dataset, etc., shall be used for retinal image processing. After the image is taken from Dataset, then retinal image processing is done by filtering the eye fundus image and resizing the eye fundus image. Different kinds of filters like Median filter, Green filter, Matched Filter, Gaussian filter, Gabor Filter can be used for image enhancement. Then the edges are Detected by using Edge Detect. Some of the edge detectors that are commonly used in Optic Disc Detection are Simple, Canny, and Prewitt edge detectors. The next process is Retinal Feature Extraction through morphological operation and Hough transform. future Optimization of Optic Disc Detection is done to detect optic disc in less computational time by Particle Swarm Optimization (PSO), Genetic Algorithm (GA), and Differential Evolution (DE). Finally, performance evaluation is done by determining the accuracy of the correctly detected optic disc of the fundus eye image. As a result, the optic disc will be obtained by retinal image processing.

Pre-processing is done to improve the image details. The images are improved by suppressing unwanted distortion or by enhancing their features. The objective of the preprocessing is to remove noise, equalization, and enhancement of image contrast. The noise removal can be done using filtering methods such as median, Wiener, and Gaussian. Image illumination and contrast can be improved by using the Contrast stretching technique. In the mean filtering method, the pixel value is exchanged with the average of the pixels in a processing window, whereas in the median filtering method, the median value of the adjacent pixels is replaced instead of the pixel value in a processing window. However, the median filter is preferred more over the mean filter [15]. 


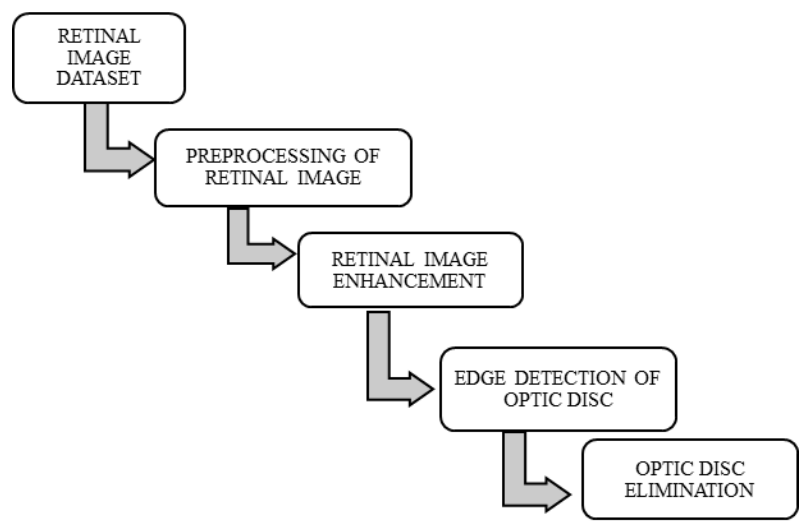

Fig. 2.1 Retinal Image Processing for Optic Disc Detection

Publicly Available Dataset

The description of the publicly available eye image databases is described in this section. A. DRIVE Dataset

The Digital Retinal Images for Vessel Extraction (DRIVE) dataset [14] [1] [7] has around 40 images, out of which 7 images have pathologies such as exudates and hemorrhages. The size of the images is $768 \times 584$ pixels with all images are compressed to the JPEG format. Each image has taken by the Canon CR5 camera which is placed at an angle of 45-degree view with a diameter of 540 pixels. Among 40 images present in the dataset, 20 of the images shall be used for training purposes while the remaining 20 images can be used for the process of testing.

B. STARE Dataset

The STARE database [4] consists of 20 images, in which 10 images have pathologies such as exudates and hemorrhages. The size of the images is $605 \times 700$ pixels. Every image has taken at the 35 -degree field of view with $650 \times 500$ pixels. Ground truth is available with this database.

C. ARIA Dataset

The ARIA ONLINE database [16] consists of the 3 groups; the first group consists of 92 images which are taken from aged people; the second group consists of 59 images that have pathologies such as exudates and hemorrhages, and the third group consists of 61 images which have pathologies such as exudates and hemorrhages. Ground truths given by experts are available with this database.

D. IMAGERET Dataset

The IMAGERET database consists of two sub-databases, DIARETDB0[2][6] and DIARETDB1[1][6][23]. DIARETDB0 has 130 images of which 20 are normal images and the remaining have pathologies such as exudates and hemorrhages. DIARETDB1has 89 images, in which 5 images are normal and the remaining have pathologies such as exudates. The size of the DIARETDB1 images is $1500 \times 1152$ pixels with all images are compressed to PNG format. Every image has taken by Canon CR5 camera at a 45-degree field of view.

E. ROC Dataset

The ROC MICRO ANEURYSM dataset comprises 100 images, out of which 50 images can be taken for training purposes and the other 50 images can be used for testing. The image size of the images in the dataset are $768 \times 576,1058 \times 1061$, and $1389 \times 1381$ pixels with all 
images are compressed to JPEG format. Every image has taken by Canon CR5 camera with a 45-degree field of view.

\section{F. VICAVR Dataset}

The VICAVR database contains 58 images, each of size of $768 \times 584$ taken by Topcon camera NW-100 model. This database has its ground truth given by three experts.

G. MESSIDOR Dataset

The MESSIDOR DATABASE [10] [3] contains 1200 images in the dataset, out of which around 800 images are taken from the dilated eye. The database images are taken by a 3CCD camera at an angle of 45 -degree view with the size of $2304 \times 1536,2240 \times 1488$, or $1440 \times$ 960 pixels, and all images are compressed in TIFF format.

TABLE I DATA SET DESCRIPTION

\begin{tabular}{|c|c|c|l|}
\hline S.NO & Dataset & $\begin{array}{c}\text { No of } \\
\text { Images }\end{array}$ & \multicolumn{1}{c|}{ Description } \\
\hline 1 & DRIVE & 40 & $\begin{array}{l}\text { The size of the images is } 768 \times 584 \text { pixels with all images } \\
\text { in the dataset are compressed to JPEG format. }\end{array}$ \\
\hline 2 & STARE & 20 & $\begin{array}{l}\text { The size of the images is } 605 \times 700 \text { pixels with every } \\
\text { image has taken at the 35-degree field of view with } 650 \times \\
500 \text { pixels. }\end{array}$ \\
\hline 4 & ARIA & 212 & $\begin{array}{l}\text { The dataset consists of the } 3 \text { groups with ground truths } \\
\text { given by experts }\end{array}$ \\
\hline 5 & IMAGERET & 219 & $\begin{array}{l}\text { The images of this dataset have taken by Canon CR5 } \\
\text { camera at a 45-degree field of view }\end{array}$ \\
\hline 7 & RICRO & 100 & $\begin{array}{l}\text { The sizes of the images are } 768 \times 576,1058 \times 1061, \text { and } \\
1389 \times 1381 \text { pixels with all images are compressed to } \\
\text { JPEG format. }\end{array}$ \\
\hline
\end{tabular}

Optic Disc Detection

$H$. The optic disc elimination shall be performed using the following four ways, which include morphological operation, Hough transform, Machine learning, and Evolutionary computing techniques.

I. Morphological Operation

$J$. The morphological operation helps to discover the new relationship or configuration which may not be so evident or which extracts the image component based on binary object value using the logical operation. Morphology is the wide group of operations for image processing, which are being processed based on shapes. Morphological operation is the extraction of features from the image. Dilation adds the pixel to the boundaries of the image. Erosion removes the pixel on the object boundaries of images and the number of pixels added or removed is based on size and structuring.

$K$. The below Table.II shows the various study on morphological operation in optic disc detection. It is inferred that most of the researchers find the optic disc using the morphological operation that uses erosion and dilation. Dilation expands the desired object 
and finds a local maximum operator. Erosion shrinks the desired object and finds the local Minimum Operator. Thus, we can use both the local Maximum Operator and Local Minimum Operator to find Morphological gradient from this gradient we can find the optic disc.

L. Hough Transform

$M$. Hough transform is a universally used technique nowadays. In an automated analysis of image due to the imperfection either in image data or either edge detection, the Hough transform method is efficient in finding an optic disc in an imperfect eye fundus image. The technique is used in the extraction of features for the image application. Generally, this technique is used in identifying the lines that are there in an image and to identify the arbitrary shapes and their positions in an image.

$N$. The below Table.III shows the various study on Hough transforms in optic disc detection. From these studies, it is concluded that by applying the circular Hough transform on an imperfect image input eye fundus image, we may locate the optic disc.

TABLE III SURVEY OF OptiC DisC DETECTION USING MORPHOLOGICAL OPERATORS

\begin{tabular}{|c|c|c|c|c|}
\hline Author & Year & Description & Merits & Demerits \\
\hline Akyol et al., & 2016 & $\begin{array}{l}\text { The author proposed a } \\
\text { method for an accurate and } \\
\text { efficient optic disc } \\
\text { segmentation of retinal } \\
\text { images which have lesions } \\
\text { and noise. }\end{array}$ & $\begin{array}{l}\text { Automatic optic } \\
\text { disc } \\
\text { segmentation is } \\
\text { Robust and } \\
\text { effective, fairly } \\
\text { reliable }\end{array}$ & $\begin{array}{l}\text { Due to the number } \\
\text { of key points } \\
\text { presents in the } \\
\text { analysis region it } \\
\text { takes a long } \\
\text { computational time } \\
\end{array}$ \\
\hline $\begin{array}{l}\text { Karunanayake } \\
\text { et al., }\end{array}$ & 2015 & $\begin{array}{l}\text { A method has been } \\
\text { proposed for partitioning of } \\
\text { the optic disc using } \\
\text { mathematical } \\
\text { morphological operations } \\
\text { and histogram specification, } \\
\text { which includes dilation and } \\
\text { erosion with appropriate } \\
\text { thresholding and circles } \\
\text { detection using the Hough } \\
\text { Transform technique. }\end{array}$ & $\begin{array}{l}\text { This method is } \\
\text { Reliable }\end{array}$ & $\begin{array}{l}\text { Takes longer } \\
\text { computational Time }\end{array}$ \\
\hline Marin et al., & 2014 & $\begin{array}{l}\text { An approach for providing } \\
\text { higher accuracy of optic } \\
\text { disc center location is } \\
\text { proposed. }\end{array}$ & $\begin{array}{l}\text { Better overall } \\
\text { performance in } \\
\text { searching the } \\
\text { optic disc }\end{array}$ & - \\
\hline Wisaeng et al., & 2014 & $\begin{array}{l}\text { An approach is proposed to } \\
\text { detect the optic disc in eye } \\
\text { images which have poor } \\
\text { quality. }\end{array}$ & $\begin{array}{l}\text { Though the } \\
\text { optic disc } \\
\text { boundary are } \\
\text { not blurred and } \\
\text { continuous the } \\
\text { OD connected } \\
\text { have Good } \\
\text { performance for } \\
\text { poor quality } \\
\text { image. }\end{array}$ & $\begin{array}{l}\text { Not fully succeeded } \\
\text { in detecting the optic } \\
\text { disc due to fuzzy } \\
\text { boundaries }\end{array}$ \\
\hline
\end{tabular}




\begin{tabular}{|l|l|l|l|l|}
\hline Prasath et al., 2000 & $\begin{array}{l}\text { A technique for automatic } \\
\text { optic disc elimination is } \\
\text { discussed in this work. }\end{array}$ & $\begin{array}{l}\text { This system can } \\
\text { be very useful } \\
\text { for poor } \\
\text { computing } \\
\text { system. }\end{array}$ & $\begin{array}{l}\text { Huge time variance } \\
\text { for different iteration } \\
\text { with same Data }\end{array}$ \\
\hline
\end{tabular}

TABLE IIII SurVey Of Optic Disc Detection Using Hough Transform

\begin{tabular}{|c|c|c|c|c|}
\hline Author & Year & Description & Merits & Demerits \\
\hline Sinha et al., & 2010 & $\begin{array}{l}\text { Proposed a method to detect } \\
\text { and localize the optic disc } \\
\text { using an Embedded, } \\
\text { Dictionary-based method. The } \\
\text { Hough transform finds the } \\
\text { curve of the optic disc } \\
\text { detection. Gaussian and } \\
\text { matched Filters are used to } \\
\text { filter the unwanted noise and } \\
\text { removing noise. }\end{array}$ & $\begin{array}{l}\text { It yields robust } \\
\text { localization of } \\
\text { Optic Disc. }\end{array}$ & $\begin{array}{l}\text { Long processing } \\
\text { time because of } \\
\text { the image of } \\
\text { different } \\
\text { resolution }\end{array}$ \\
\hline $\begin{array}{l}\text { Karunanayake et } \\
\text { al., }\end{array}$ & 2015 & $\begin{array}{l}\text { Proposed a method for the } \\
\text { optic disc partitioning of the } \\
\text { optic disc using mathematical } \\
\text { morphological operations and } \\
\text { histogram specification. The } \\
\text { histogram definition is derived } \\
\text { from the intensity of RGB } \\
\text { pictures, and mathematical } \\
\text { Morphology extracts an } \\
\text { image's feature. }\end{array}$ & Reliable & $\begin{array}{l}\text { Takes longer } \\
\text { computational } \\
\text { Time }\end{array}$ \\
\hline Marin et al., & 2014 & $\begin{array}{l}\text { In this, the author proposed a } \\
\text { method and used } \\
\text { morphological operation for the } \\
\text { extraction of the feature of } \\
\text { image Erosion and dilation to } \\
\text { fill the breaks and holes. }\end{array}$ & $\begin{array}{l}\text { Better overall } \\
\text { performance }\end{array}$ & - \\
\hline Dehghani et al., & 2012 & $\begin{array}{l}\text { This work uses Histogram } \\
\text { matching to finds the histogram } \\
\text { of images in RGB and } \\
\text { Template matching to find the } \\
\text { match of RGB value from the } \\
\text { template. }\end{array}$ & $\begin{array}{l}\text { Tolerate the vast } \\
\text { variety of image } \\
\text { characteristic }\end{array}$ & - \\
\hline
\end{tabular}

\section{O. Machine Learning}

The machine learning Technique provides an effective way for finding the optic disc even when the object size is resized. Machine learning effectively maps the old coordinates to the new coordinates by scaling factors.

The below Table.IV shows the study of various machine learning methods in optic disc detection. This review work was conducted based on the image processing technique on basis of machine learning techniques used in optic disc detection. It is inferred that the usage of 
machine learning techniques can able to detect optic disc through a supervised machine learning algorithm. The most widely used supervised algorithms are Support vector machines, Neural networks, K-NN Regressor, which are effective in finding the optic disc when the image size is resized.

\section{P. Evolutionary Computing Technique}

The evolutionary computing technique is an optimization technique that uses Darwinian's natural evolution process to determine the optic disc location from the randomly chosen coordinates in an image.

Table. V shows the study on various Evolutionary computing techniques in optic disc detection. From the study, it is inferred that by using the Evolutionary computing technique, we can able to find the optic disc through the optimized technique such as Particle Swarm Optimization (PSO), Genetic Algorithm (GA), and Differential Evolution (DE). Evolutionary computing techniques can able to find an optic disc in both brighter and darker intensity regions whereas the traditional method failed to detect the optic disc at brighter images.

TABLE IV SuRvey Of Optic Disc Detection Using MachinE LEARNING

\begin{tabular}{|c|c|c|c|c|}
\hline Author & Year & Description & Merits & Demerits \\
\hline Niemeijer et al., & 2009 & $\begin{array}{l}\text { In this work, a kNN regressor } \\
\text { is used to estimate the } \\
\text { distance between pixels in an } \\
\text { image and the item of } \\
\text { interest, }\end{array}$ & $\begin{array}{l}\text { It gives Good } \\
\text { performance }\end{array}$ & - \\
\hline Gupta et al., & 2015 & $\begin{array}{l}\text { An Automatic retinal } \\
\text { screening is done to detect } \\
\text { retinal microaneurysms, } \\
\text { exudates and the optic disc is } \\
\text { proposed. }\end{array}$ & $\begin{array}{l}\text { Efficient for low- } \\
\text { quality images. }\end{array}$ & $\begin{array}{l}\text { Computation } \\
\text { time too long }\end{array}$ \\
\hline Lakshman et al., & 2013 & $\begin{array}{l}\text { This work deals with the } \\
\text { analysis of retinal image } \\
\text { analysis for the effective } \\
\text { detection of optic disc and } \\
\text { exudates. }\end{array}$ & $\begin{array}{l}\text { It Avoids false } \\
\text { Edge pixel } \\
\text { detection }\end{array}$ & $\begin{array}{l}\text { The problem of } \\
\text { the presence of a } \\
\text { severe lesion in } \\
\text { Retinal fundus } \\
\text { images }\end{array}$ \\
\hline Abirami et al., & 2015 & $\begin{array}{l}\text { The Optic cup and optic disc } \\
\text { segmentation were } \\
\text { determined and segmented is } \\
\text { done using grow cut } \\
\text { algorithm. }\end{array}$ & $\begin{array}{l}\text { Efficient Results } \\
\text { can be detected } \\
\text { using optic cup } \\
\& \text { disc in texture } \\
\text { based retinal } \\
\text { Image }\end{array}$ & $\begin{array}{l}\text { A region is } \\
\text { presently given } \\
\text { manually, which } \\
\text { may be made } \\
\text { automatically }\end{array}$ \\
\hline Farooq et al., & 2015 & $\begin{array}{l}\text { They proposed a method to } \\
\text { detect and eliminate optic } \\
\text { disc using SVM }\end{array}$ & $\begin{array}{l}\text { Identification of } \\
\text { the optic disc is } \\
\text { done in lesser } \\
\text { time. }\end{array}$ & $\begin{array}{l}\text { Size and density } \\
\text { of optic disc } \\
\text { difficult to find. }\end{array}$ \\
\hline Jeffery et al., & 2016 & $\begin{array}{l}\text { They proposed a method to } \\
\text { locate the optic disc in eye } \\
\text { fundus images using the } \\
\text { shortest path approach }\end{array}$ & $\begin{array}{l}\text { The optic disc can } \\
\text { be easily identified } \\
\text { where there is less } \\
\text { lesion }\end{array}$ & $\begin{array}{l}\text { Difficult in } \\
\text { finding highly } \\
\text { variable } \\
\text { appearance in } \\
\text { Retinal images }\end{array}$ \\
\hline
\end{tabular}


TABLE V

Survey Of Optic Disc Detection Using Evolutionary Computing TeChniQues

\begin{tabular}{|c|c|c|c|c|}
\hline Author & Year & Description & Merits & Demerits \\
\hline Kar et al., & 2015 & $\begin{array}{l}\text { The author proposed work } \\
\text { on the diagnosis of retinal } \\
\text { disorders through the } \\
\text { extraction of retinal blood } \\
\text { vessel information through } \\
\text { differential evolution, }\end{array}$ & $\begin{array}{l}\text { The contrast of an } \\
\text { image is reduced by } \\
20 \% \\
\text { High detection } \\
\text { accuracy than other } \\
\text { methods. }\end{array}$ & $\begin{array}{l}\text { This method fails to } \\
\text { detect the thin and } \\
\text { weak vessel }\end{array}$ \\
\hline Dias et al., & 2012 & $\begin{array}{l}\text { In this work, Ant colony } \\
\text { Optimization is used to } \\
\text { detect edges and to } \\
\text { localize the optic disc. }\end{array}$ & $\begin{array}{l}\text { Simple and } \\
\text { computationally } \\
\text { efficient. }\end{array}$ & $\begin{array}{l}\text { Theoretical analysis } \\
\text { is difficult. }\end{array}$ \\
\hline Carmona et al., & 2008 & $\begin{array}{l}\text { In this work Genetic } \\
\text { algorithm is used to } \\
\text { determine the optic disc } \\
\text { and localize it. }\end{array}$ & $\begin{array}{l}\text { Robustness can be } \\
\text { seen in high } \\
\text { performance in optic } \\
\text { disc Detection }\end{array}$ & $\begin{array}{l}\text { Additionally } \\
\text { penalized since mat } \\
\text { lab is an interpreted } \\
\text { language }\end{array}$ \\
\hline Burman et al., & 2013 & $\begin{array}{l}\text { In this work, Multilevel } \\
\text { thresholding is achieved } \\
\text { through } \\
\text { evolution }\end{array}$ & $\begin{array}{l}\text { Real-time Image } \\
\text { Segmentation and } \\
\text { Reorganization } \\
\text { problem. }\end{array}$ & $\begin{array}{l}\text { Accuracy to be } \\
\text { improved in finding } \\
\text { the object. }\end{array}$ \\
\hline Ponnaiah et al., & 2013 & $\begin{array}{l}\text { Proposed a method to } \\
\text { improve the performance } \\
\text { using weighted error rate. }\end{array}$ & $\begin{array}{l}\text { Randomly choose } \\
\text { the optic disc region } \\
\text { so the optic disc } \\
\text { region can be found } \\
\text { very fast. }\end{array}$ & $\begin{array}{l}\text { Not efficient for all } \\
\text { types of images. } \\
\text { Sometimes it can } \\
\text { take a long time to } \\
\text { converge. }\end{array}$ \\
\hline $\begin{array}{l}\text { Vinoth Kumar et } \\
\text { al., }\end{array}$ & 2017 & $\begin{array}{l}\text { Localization of } \text { optic disc } \\
\text { is made through } \\
\text { Differential } \\
\text { with Memetic search } \\
\text { capability }\end{array}$ & $\begin{array}{l}\text { The convergence } \\
\text { rate is improved }\end{array}$ & $\begin{array}{l}\text { Reliability has to be } \\
\text { improved }\end{array}$ \\
\hline
\end{tabular}

\section{Performance Evaluation}

Performance analysis is done based on determining the accuracy obtained by optic disc detection in an eye fundus image. The formula for determining accuracy is given in equation (1). Result analysis is done for each technique separately, and the accuracy of optic disc detection is determined based on the number of optic discs detected correctly in eye fundus images.

Where,

$$
\text { Accuracy }=\frac{(T P+T N)}{(T P+T N+F P+F N)}
$$

\footnotetext{
TP - True Positive,

TN - True Negative,

FP - False Positive,

FN - False Negative.
} 
Table. VI shows the performance of various study work that took place in the area of optic disc localization.

TABLE VI PERFormanCE ANALYSIS ON VARIOUS DATASETS

\begin{tabular}{|c|c|c|c|}
\hline Author & Year & Dataset & Accuracy \\
\hline \multirow{3}{*}{ Akyol et al., } & \multirow{3}{*}{2016} & DIARETDB1 & $94.38 \%$ \\
\hline & & DRIVE & $95 \%$ \\
\hline & & $\mathrm{ROC}$ & $90 \%$ \\
\hline Prasath et al., & 2000 & $\begin{array}{l}\text { ARAVIND EYE HOSPITAL-MADURAI, } \\
\text { STARE AND DRIVE }\end{array}$ & $93 \%$ \\
\hline \multirow{2}{*}{ Karunanayake et al., } & \multirow{2}{*}{2015} & DIARET DB0 & $90.7 \%$ \\
\hline & & DIARET DB1 & $89.8 \%$ \\
\hline \multirow{2}{*}{ Wisaeng et al., } & \multirow{2}{*}{2014} & LOCAL DATASET & $97.61 \%$ \\
\hline & & STARE & $97.61 \%$ \\
\hline \multirow{3}{*}{ Sinha et al., } & \multirow{3}{*}{2012} & DIRETDB0 & $96.9 \%$ \\
\hline & & DIRETDB1 & $100 \%$ \\
\hline & & DRIVE & $95 \%$ \\
\hline \multirow{3}{*}{ Dehghani et al., } & \multirow{3}{*}{2012} & STARE & $91.36 \%$ \\
\hline & & DRIVE & $100 \%$ \\
\hline & & LOCAL DATASET & $98.9 \%$ \\
\hline Gupta et al., & 2015 & MESSIDOR & $86 \%$ \\
\hline Lakshman et al., & 2013 & LOCAL DATASET & $98 \%$ \\
\hline \multirow{2}{*}{ Farooq et al., } & \multirow{2}{*}{2015} & MESSIDOR & $90 \%$ \\
\hline & & STARE & $100 \%$ \\
\hline \multirow{3}{*}{ Wigdahl et al., } & \multirow{3}{*}{2017} & DIARET DB1 & $98.88 \%$ \\
\hline & & DRIVE & $100 \%$ \\
\hline & & MESSIDOR & $99.42 \%$ \\
\hline Kar et al., & 2015 & DRIVE & $97 \%$ \\
\hline Dias et al., & 2012 & DRIVE & $100 \%$ \\
\hline
\end{tabular}

\section{Conclusion}

In this work, an extensive study has been accomplished on different approaches for optic disc localization in a human eye fundus image. This study also showcases the publicly available datasets for this application. The survey also shows the accuracy of optic disc localization achieved by different approaches such as traditional methods and evolutionary techniques. From this study, it has been found that evolutionary algorithms give better results when comparing them with other techniques. The future direction includes the usage of memetic techniques to improve the performance of the optic disc localization in an eye fundus image. 


\section{References}

[1] Akyol K, Şen B, Bayır Ş. Automatic Detection of Optic Disc in Retinal Image by Using Keypoint Detection, Texture Analysis, and Visual Dictionary Techniques. Computational and Mathematical Methods in Medicine. 2016;2016:1-10.

[2] Karunanayake N, Gnanasekera M, Kodikara N. An Improved Method for Optic Disc Localization. International Journal of Computer Applications. 2015;128(13):25-28.

[3] Marin D, Gegundez-Arias M, Suero A, Bravo J. Obtaining optic disc center and pixel region by automatic thresholding methods on morphologically processed fundus images. Computer Methods and Programs in Biomedicine. 2015;118(2):173-185.

[4] Wisaeng K, Hiransakolwong N, Pothiruk E. Automatic Detection of Optic Disc in Digital Retinal Images. International Journal of Computer Applications. 2014;90(5):15-20.

[5] Prasath A, Ramya M. Automatic Detection and Elimination of an Optic Disc for Improving Drusen Detection Accuracy. 2014 Fifth International Conference on Signal and Image Processing. 2014;

[6] Sinha N, Babu R. Optic disk localization using L $<$ inf $>1</$ inf $>$ minimization. 2012 19th IEEE International Conference on Image Processing. 2012;.

[7] Dehghani A, Moghaddam H, Moin M. Optic disc localization in retinal images using histogram matching. EURASIP Journal on Image and Video Processing. 2012;2012(1).

[8] Niemeijer M, Abràmoff $M$, van Ginneken B. Fast detection of the optic disc and fovea in color fundus photographs. Medical Image Analysis. 2009;13(6):859-870. Niemeijer M, Abràmoff M, van Ginneken B. Fast detection of the optic disc and fovea in color fundus photographs. Medical Image Analysis. 2009;13(6):859-870.

[9] Gupta S KAM. Diagnosis of Diabetic Retinopathy using Machine Learning. J Res Development. 2015; http://dx.doi.org/10.4172/2311-3278.1000127

[10] R R, Lakshman B. Retinal Image Analysis Using Morphological Process and Clustering Technique. Signal \& Image Processing : An International Journal. 2013;4(6):55-69.

[11] Abirami, P. K., Ganga, T. K., Regina, I. A., \& Geetha, S. Neural Network based Classification and Detection of Glaucoma using Optic Disc and CUP Features. International Journal of Scientific Research Engineering \& Technology. 2015;4.

[12] Farooq U, Sattar N. Improved automatic localization of optic disc in Retinal Fundus using image enhancement techniques and SVM. 2015 IEEE International Conference on Control System, Computing and Engineering (ICCSCE). 2015;

[13] Wigdahl, J., Guimaraes, P., \& Ruggeri, A. A shortest path approach to optic disc detection in retinal fundus images. Journal for Modeling in Ophthalmology,. 2017;1(4):29-42.

[14] Kar S, Maity S. Blood vessel extraction with optic disc removal in retinal images. 2015 Eighth International Conference on Advances in Pattern Recognition (ICAPR). 2015;

[15] FerdicMashakPonnaiah G, Santhosh Baboo S. GA based Automatic Optic Disc Detection from Fundus Image using Blue Channel and Green Channel Information. International Journal of Computer Applications. 2013;69(2):23-31.

[16] Arnay R, Fumero F, Sigut J. Ant Colony Optimization-based method for optic cup segmentation in retinal images. Applied Soft Computing. 2017;52:409-417.

[17] Carmona E, Rincón M, García-Feijoó J, Martínez-de-la-Casa J. Identification of the optic nerve head with genetic algorithms. Artificial Intelligence in Medicine. 2008;43(3):243-259.

[18] Burman R, Paul S, Das S. A differential evolution approach to multi-level image thresholding using type II fuzzy sets. In: Swarm, Evolutionary, and Memetic Computing. Cham: Springer International Publishing; 2013. p. 274-85.

[19] Ponnaiah M, Baboo S. Automatic Optic Disc Detection and Removal of False Exudates for Improving Retinopathy Classification Accuracy. 2013.

[20] Dias MA, Monteiro FC. Optic disc detection using ant colony optimization. Numerical Analysis and Applied Mathematics ICNAAM 2012: International Conference of Numerical Analysis and Applied Mathematics. 2012;1479(1):798-801.

[21] Kumar BV, Janani K, Priya NM. A survey on automatic detection of hard exudates in diabetic retinopathy. In: 2017 International Conference on Inventive Systems and Control (ICISC). IEEE; 2017. 
[22] Vinoth Kumar B, Karpagam GR, Zhao Y. Evolutionary algorithm with memetic search capability for optic disc localization in retinal fundus images. In: Intelligent Data Analysis for Biomedical Applications. Elsevier; 2019. p. 191-207.

[23] Kauppi T, Kalesnykiene V, Kamarainen J-K, Lensu L, Sorri I, Raninen A, et al. the DIARETDB1 diabetic retinopathy database and evaluation protocol. In: Procedings of the British Machine Vision Conference 2007. British Machine Vision Association; 2007.

[24] Vinoth Kumar B, Sabareeswaran S, Madumitha G. A decennary survey on artificial intelligence methods for image segmentation. In: Advanced Engineering Optimization Through Intelligent Techniques. Singapore: Springer Singapore; 2020. p. 291-311.

[25] Rajesh R, Mathivanan B. Predicting Flight Delay using ANN with Multicore Map reduce framework, Communication and Power Engineering. In Walter de Gruyter GmbH \& Co KG; 2017.

[26] Devi I, Karpagam GR, Kumar BV. A survey of machine learning techniques. Int J Comput Syst Eng. 2017;3(4):203.

[27] Prakash, J., \& Kumar, B. V. (2021). An empirical analysis of hierarchical and partition-based clustering techniques in optic disc segmentation. Intelligent Learning for Computer Vision, 8596. https://doi.org/10.1007/978-981-33-4582-9_7 